\title{
How do emergency departments and emergency leaders catalyze positive change through quality improvement collaborations?
}

\author{
Lucas B. Chartier, MD CM, MPH ${ }^{*}$; Shawn E. Mondoux, MD, MSc ${ }^{\ddagger \S}$; Antonia S. Stang, MD CM, MBA,

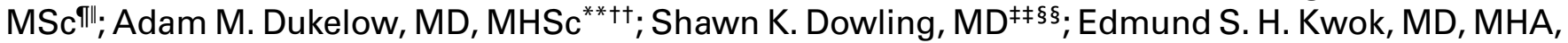 \\ MScIf; Sachin V. Trivedi, MD"li; Joshua Tepper, MD, MPP, MPH, MBA ${ }^{* * *+\dagger}$; Eddy Lang, MD CM ${ }^{\ddagger \neq \S \S ~}$
}

\section{ABSTRACT}

Objectives: Quality Improvement and Patient Safety (QIPS) plays an important role in addressing shortcomings in optimal healthcare delivery. However, there is little published guidance available for emergency department (ED) teams with respect to developing their own QIPS programs. We sought to create recommendations for established and aspiring ED leaders to use as a pathway to better patient care through programmatic QIPS activities, starting internally and working towards interdepartmental collaboration.

Methods: An expert panel comprised of ten ED clinicians with QIPS and leadership expertise was established. A scoping review was conducted to identify published literature on establishing QIPS programs and frameworks in healthcare. Stakeholder consultations were conducted among Canadian healthcare leaders, and recommendations were drafted by the expert panel based on all the accumulated information. These were reviewed and refined at the 2018 CAEP Academic Symposium in Calgary using in-person and technologically-supported feedback.

Results: Recommendations include: creating a sense of urgency for improvement; engaging relevant stakeholders and leaders; creating a formal local OIPS Committee; securing funding and resources; obtaining local data to guide the work; supporting QIPS training for team members; encouraging interprofessional, cross-departmental, and patient collaborations; using an established QIPS framework to guide the work; developing reward mechanisms and incentive structures; and considering to start small by focusing on a project rather than a program.

Conclusion: A list of 10 recommendations is presented as guiding principles for the establishment and sustainable deployment of QIPS activities in EDs throughout Canada and abroad. ED leaders are encouraged to implement our recommendations in an effort to improve patient care.

\section{RÉSUMÉ}

Objectif: L'amélioration de la qualité et la sécurité des patients (AQSP) joue un rôle important dans la correction des lacunes observées dans la prestation optimale de soins. Toutefois, les équipes de soins au service des urgences (SU) disposent de peu de documentation sur la conception de leurs propres programmes d'AQSP. L'étude avait donc pour objectif l'élaboration de recommandations conçues à l'intention des chefs de file, nouveaux ou confirmés, au SU, et présentées comme une voie à emprunter pour améliorer les soins aux patients, par l'application d'activités programmatiques d'AQSP, tout d'abord au sein du service, puis entre services, grâce à la collaboration.

Méthode: Un groupe d'experts composé de 10 cliniciens en médecine d'urgence, ayant des compétences particulières en AQSP et en pouvoir d'influence, a été mis sur pied. Un examen de cadrage a été entrepris à la recherche de publications sur l'établissement de programmes d'AQSP et de cadres de travail s'y rapportant, en soins de santé. Des consultations

From: *University Health Network, Emergency Department, Toronto, ON; †University of Toronto, Department of Medicine, Division of Emergency Medicine, Toronto, ON; ¥Hamilton Health Sciences, Emergency Department, Hamilton, ON; §McMaster University, Department of Medicine, Division of Emergency Medicine, Hamilton, ON; đUniversity of Calgary Departments of Pediatrics, Community Health Science, Emergency Medicine, Calgary, AB; \|Alberta Children's Hospital Research Institute, Calgary, AB; **London Health Sciences Centre, Department of Emergency Medicine, London, ON; ††University of Western Ontario, Department of Medicine, Division of Emergency Medicine, London, ON; $¥ \ddagger$ Department of Emergency Medicine, Cumming School of Medicine, University of Calgary, Calgary, AB; §§Department of Emergency Medicine, Alberta Health Services, Calgary, AB; १ीDepartment of Emergency Medicine, University of Ottawa, Ottawa, ON; llIDepartment of Emergency Medicine, University of Saskatchewan, Saskatoon, SK; ${ }^{* *}$ North York General Hospital, Toronto, ON; and the †††Department of Family and Community Medicine, University of Toronto, Toronto, ON.

Correspondence to: Dr. Lucas B Chartier, 200 Elizabeth St., RFE-GS-480, Toronto, ON, M5G 2C4; Email: lucas.chartier@uhn.ca

(C) Canadian Association of Emergency Physicians

CAEP | ACMU
CJEM 2019;21(4):542-549

DOI 10.1017/cem.2019.25 
ont été menées avec les parties intéressées parmi les chefs de file en soins de santé au Canada, et le groupe d'experts a rédigé une version préliminaire de recommandations fondées sur l'ensemble de l'information recueillie. Celles-ci ont été examinées et améliorées durant le Symposium sur les affaires universitaires 2018 de l'ACMU, à Calgary, à la suite de rétroactions communiquées en personne ou par voie électronique.

Résultats: Les recommandations portaient sur : I'éveil d'un sentiment d'urgence à l'égard de l'amélioration; la mobilisation d'intervenants et de chefs de file compétents; la mise sur pied d'un comité local structuré d'AQSP; I'obtention de financement et de ressources; la disponibilité de données locales pour orienter le travail; le soutien de la formation des membres d'équipe en AQSP; la promotion de la collaboration entre professions, entre services et avec les patients; I'utilisation d'un cadre de travail d'AQSP déjà établi afin d'orienter le travail; I'élaboration d'un système de récompenses et de structures incitatives; la possibilité d'entreprendre, au début, des initiatives à petite échelle, soit des projets plutôt que des programmes.

Conclusion: Les dix recommandations ont été présentées à titre de principes directeurs en vue de l'élaboration d'activités d'AQSP et de leur mise en œuvre durable dans les SU, au Canada et ailleurs dans le monde. Les chefs de file dans les SU sont invités à appliquer ces recommandations dans le but d'améliorer les soins aux patients.

Keywords: Emergency service, hospital, quality improvement, patient safety, program development, leadership, quality of health care

\section{INTRODUCTION}

Both experts and patients agree that our health care delivery system has many opportunities for improvement. ${ }^{1-5}$ In recent health care system performance rankings by the Commonwealth Fund, Canada ranks ninth overall among 11 high-income countries. ${ }^{6}$ In another study, $60 \%$ of Canadians reported that fundamental changes were needed in our health care system, and only $28 \%$ were "very confident" that they would receive high-quality care.

The suboptimal performance of our current system is multifactorial. ${ }^{8}$ It is our role, as emergency physicians (EPs) at the intersection of the community and hospitals and of general and specialized care, to see these issues as opportunities for improvement. The burgeoning field of quality improvement and patient safety (QIPS) has had a growing impact on health care institutions in our country since the publication of the Institute of Medicine (IOM) reports almost two decades ago. ${ }^{9,10}$ With its focus on smaller-scale iterative design, QIPS may be the most viable philosophy and science at our disposal to improve care delivery in our health system.
However, for EPs to improve care within their emergency departments (EDs) and hospitals, emergency medicine (EM) leaders and departments need to invest in QIPS as a framework. We are unaware of any national bodies that have provided recommendations to improve the system capacity to conduct QIPS work in the ED. The objectives of this 2018 CAEP Academic Symposium panel are to address this gap by:

- Identifying the barriers, facilitators and the current Canadian context for the pursuit of QIPS projects in the ED setting through a national survey and literature review.

- Providing guidance on the development of ED capacity aimed at supporting and leading interdepartmental QIPS projects, through best-practice recommendations on how to build a local QIPS program.

- Providing a collection of relevant resources available for ED clinicians interested in QIPS.

\section{METHODOLOGY}

\section{Expert panel process}

We formed an expert panel, which included nine EPs and one EM resident affiliated with six different Canadian medical schools. The expert panel members were explicitly selected based on their expertise, roles in QIPS, and geographic representation. They ranged in leadership roles from front-line clinicians to heads of quality programs, research program, and departments.

The panel developed a draft of a list of recommendations based on their academic expertise and professional experience, which was iteratively improved through a scoping review of the topic. Subsequently, the panel communicated with 14 of their personal contacts who are national experts on QIPS, for their commentary on the list. These included medico-legal experts, hospital executives, and EM academic leaders. Based on their feedback and through seven monthly teleconference meetings, the list was refined. The literature was then reviewed to confirm, support, and exemplify the recommendations.

\section{Environmental scan of Canadian QIPS activities}

As part of our preparatory work, we conducted a national survey of university EM department chairs, major academic hospital ED chiefs, and QIPS leads at all 17 
Canadian university-affiliated academic centres. The objective was to better understand the operational and academic environments in which QIPS activities are taking place, and the full results have been published concurrently with this article in CFEM. ${ }^{11}$ It found significant local educational and academic efforts for QIPS in Canadian EM, with a discrepancy between the level of formal support/infrastructure and the output of such activities. ${ }^{11}$

\section{CAEP 2018 Academic Symposium process}

The results of the national survey and draft recommendations were presented at the 2018 CAEP Academic Symposium on May 26, 2018, in Calgary, $\mathrm{AB}$, to an audience of 82 members. The panel used a four-prong technique to elicit feedback on the list of recommendations: 1) paperbased lists distributed to the Symposium attendees for written feedback; 2) verbal discussion between the panel and attendees; 3) Twitter comments/polls for those not on-site; and 4) an innovative crowd-sourcing platform called PollEverywhere ${ }^{\circledR}$ (San Francisco, CA, USA). Through this platform, the panel was able to collect the audience's demographics, their votes on each of the recommendations (i.e., accept, modify, and reject), and comments submitted on their smartphone or computer that were projected in real-time on the room's main screen. This allowed for semi-quantitative and qualitative feedback that supported the discussions at the Symposium and informed this paper. Table 1 shows a summary of the self-reported demographics of the 45 (54.9\%) attendees who replied to the survey in real-time.

\section{RECOMMENDATIONS}

As a provider or leader interested in developing a local EM-based QIPS program, the following steps are recommended to increase the feasibility and sustainability of initiatives that will lead to improved patient care (Table 2).

\section{Recommendation 1. Use patient or provider stories to create urgency and engagement for a culture of improvement}

Effective change management through QIPS requires building a platform that will engage individuals and enable the procurement of necessary resources. This

\begin{tabular}{|c|c|}
\hline Demographics & $\begin{array}{l}\text { Responses } \\
\mathrm{n}(\%)\end{array}$ \\
\hline \multicolumn{2}{|l|}{ Age $(n=44)$} \\
\hline$<35$ years & $8(18.2 \%)$ \\
\hline $35-44$ & $16(36.4 \%)$ \\
\hline $45-54$ & $8(18.2 \%)$ \\
\hline $55-64$ & $9(20.5 \%)$ \\
\hline$\geq 65$ & $3(6.8 \%)$ \\
\hline \multicolumn{2}{|l|}{ Gender $(n=43)$} \\
\hline Male & $28(65.1 \%)$ \\
\hline Female & $15(34.9 \%)$ \\
\hline \multicolumn{2}{|l|}{ Practice setting $(n=43)$} \\
\hline Urban academic & $41(95.3 \%)$ \\
\hline Rural academic & $1(2.3 \%)$ \\
\hline Urban community & $1(2.3 \%)$ \\
\hline \multicolumn{2}{|l|}{ QIPS experience $(n=45)$} \\
\hline Interested & $8(17.8 \%)$ \\
\hline Beginner & $12(26.7 \%)$ \\
\hline Novice & $17(37.8 \%)$ \\
\hline Expert & $8(17.8 \%)$ \\
\hline \multicolumn{2}{|l|}{ Leadership experience $(n=45)$} \\
\hline Learner & $3(6.7 \%)$ \\
\hline Clinical MD without leadership aspirations & $4(8.9 \%)$ \\
\hline Aspiring leader & $11(24.4 \%)$ \\
\hline Current leader & $27(60.0 \%)$ \\
\hline
\end{tabular}

case for system-level change may be built through seminal literature, ${ }^{9,10}$ local patient/provider stories or broader goal setting by inspiring leaders. ${ }^{12}$ Breakthrough performance goals, as well as local aim and vision, are required to improve system-level performance and execute QIPS projects. ${ }^{13-15}$ One key success factor to achieve these is engaging physicians, providers, and administrators in a common purpose, as they are more likely to support change when they understand the "why" behind the movement. ${ }^{12,16}$ Over time, a platform for quality at a system and local level will enable improvement and shift to an organizational culture of improvement.

\section{Recommendation 2. Engage all relevant stakeholders for the coordination of QIPS work, which may include institutional, departmental, university, and regional leadership, as well as patients}

Specific stakeholders and support will vary depending on the institution, but they should typically include ED 
Table 2. Recommendations from Panel 1 on QIPS of the 2018 CAEP Academic Symposium on Leadership

1. Use patient or provider stories to create urgency and engagement for a culture of improvement

2. Engage all relevant stakeholders for the coordination of QIPS work, which may include institutional, departmental, university, and regional leadership, as well as patients

3. Create a formal ED QIPS committee with goals, terms of references, and clearly defined roles and responsibilities

4. Secure funding, resources, and protected time required to enable successful ongoing QIPS work

5. Local data must be available to identify and prioritize opportunities for improvement, guide project selection and design, and track improvements

6. Encourage, support, and recognize training in QIPS methodologies for EM physician and all health care providers including support staff

7. Interprofessional, cross-departmental, and patient collaboration is vital for the design of broad-based projects to ensure engagement of stakeholders

8. Use an established QIPS framework and adapt interventions to your local context

9. Encourage reward mechanisms and incentive structures that align with the goals of the program team members

10. In centres with no QIPS experience, consider starting small by focusing on a project or specific deliverable instead of a program

leadership and senior hospital leaders such as chairs of the institutional quality/safety committee or affiliated university academic leaders, as well as patients. ${ }^{17,18}$ Reciprocally, members of the ED QIPS team may seek membership on hospital or university-wide QIPS committees to ensure communication and alignment and to enable collaboration. Although the support from the various stakeholders would ideally include financial resources and should be confirmed in writing, other goals may include support through administrative access to hospital resources (e.g., data analyst and QIPS experts).

\section{Recommendation 3. Create a formal ED QIPS committee with goals, terms of references, and clearly defined roles and responsibilities}

The creation of a diverse ED QIPS committee (ideally co-led by a physician and non-physician) supports successful and sustainable QIPS initiatives in the clinical setting. The terms of reference, responsibilities and goals, should support the vision previously determined with the relevant stakeholders. ${ }^{17}$ Having a physician champion is crucial for the engagement of other physicians in the development of new QIPS initiatives, and the same holds true for nursing and interprofessional leadership. ${ }^{19}$ Regularly planned meetings (e.g., monthly or quarterly) and a clear reporting structure will increase accountability, alignment, opportunities, and momentum for the committee. ${ }^{20}$ Three-way communication focused on project progression between the QIPS committee, the front-line providers interested in participating in projects, and the leadership team (both ED and hospital-wide) is essential. The ultimate goal is to have the QIPS committee serve as a vector to align the workforce and leaders on projects and priorities, as opposed to being tasked with the conduct of all aspects of improvement and operations of the ED.

\section{Recommendation 4. Secure funding, resources, and protected time required to enable successful ongoing QIPS work}

A comprehensive literature review of local contextual factors found that funding, general resources, and time were most positively associated with QIPS success, ${ }^{21}$ and workload was most negatively related to successful implementation. ${ }^{22}$ Funding alone is, therefore, not sufficient for QIPS success, and resources and time also play an important role. ${ }^{23}$ These findings highlight the importance of protected time for front-line caregivers to perform meaningful QIPS work. They also emphasize the importance of access to resources that could include access to individuals with QIPS methodological expertise, administrative support, project management, and data and analytics support. Without access to these crucial elements of successful project design, implementation, and evaluation, it may be unreasonable to expect success. Depending on the size of the ED and the scope of the QIPS projects, these resources could be supported and shared across departments, hospitals, or the university.

\section{Recommendation 5. Local data must be available to identify and prioritize opportunities for improvement, guide project selection and design, and track improvements}

System-level metrics and data are necessary for system improvements, with regular feedback loops being an essential component. ${ }^{12}$ Access to local and timely data in some form is important to all QIPS initiatives. ${ }^{24}$ 
Preliminary and historical data (e.g., patient safety incident reports) are useful to understand root causes and the magnitude of adverse events, set improvement goals, and benchmark against peers. ${ }^{24-26}$ While near real-time updates and accepted benchmarks help the most, in many settings, these data may not be available. Leaders should then facilitate QIPS team members to have access to organizational resources such as decision support services or information technology to query existing databases with new questions. If there is no database to query, QIPS team members can be empowered and supported to collect their own data through direct observation or chart review, even if the sample size is small. ${ }^{27}$ As QIPS efforts move forward, prospective purposeful data collection enables measuring the effect of any intervention. ${ }^{15,28-30}$

\section{Recommendation 6. Encourage, support, and recognize training in QIPS methodologies for EM physicians and all health care providers including support staff}

QIPS team skills have been identified as an important contextual factor in QIPS success. ${ }^{23}$ The importance of training in QIPS is underscored by the prominence of quality and safety competencies and milestones in CanMEDS 2015. ${ }^{31}$ To build a successful QIPS program, EDs should focus on:

1. Encouraging a minimum QIPS literacy requirement for physicians to ensure commitment to system improvements and capacity for project involvement;

2. Providing QIPS continuous professional development (CPD) opportunities and training sessions for nurses, allied health providers, and trainees to support interdisciplinary teams; and

3. Providing and supporting enhanced QIPS learning opportunities for individuals who are interested in leading QIPS projects, including nurturing mentorship relationships.

Numerous approaches and levels of QIPS training have been developed in recent years, ranging from the basic online modules to graduate-level experiential degrees and including a variety of certificates, practical opportunities, and workshops. ${ }^{32}$ We developed a comprehensive list of QIPS educational opportunities and resources, available online on CAEP's website at https://caep.ca/qips-resources/.
Recommendation 7. Interprofessional, cross-departmental, and patient collaboration is vital for the design of broad-based projects to ensure engagement of stakeholders

Most QIPS projects affect multiple stakeholders including patients and providers from other departments. ${ }^{19}$ Various tools can be used for "stakeholder mapping," which allows a deeper understanding of the project contributors' expected involvement based on power and interest. ${ }^{33,34}$ Additionally, a challenging, but important, facet of QIPS projects is the involvement of patients and families, when feasible. This is done to align the work with the expectations of those who arguably matter most, to ensure their perspectives and values are incorporated. Increasingly, approaches and toolkits are being developed to facilitate this important part of QIPS projects and bring the patients' voice to the table. ${ }^{35}$ Finally, obtaining the support of an executive sponsor, who will openly support and promote the project, open doors, and facilitate buy-in, is crucial to the success of QIPS projects. ${ }^{36}$

\section{Recommendation 8. Use an established QIPS framework and adapt interventions to your local context}

The systematic use of an improvement framework or methodology is essential to improve systems reliably rather than individual providers' variable behaviours. ${ }^{37-39}$ The Model for Improvement, Plan-Do-Study-Act (PDSA) cycles, SMART aim statements, Six Sigma, Toyota Production System/Lean Production, and Root cause analysis are common examples of methodologies utilized in health care today. ${ }^{15,24}$ Given that all methodologies share common features (e.g., goal setting, systematic observation and analysis, rapid cycle improvement, and iterative measurement), ED leaders creating a new QIPS program should likely start by training a core group on one methodology and spread the chosen methodology through their group. Over time, expanding the methodological repertoire to enable different approaches to different problems will likely increase the success rate of QIPS initiatives.

\section{Recommendation 9. Encourage reward mechanisms and incentive structures that align with the goals of the program team members}

The sustainability planning of projects and programs is an oft-forgotten, but crucially important, factor to 
ensure the continuous engagement of providers in system improvements. ${ }^{40,41}$ The development of reward mechanisms and incentives structures are an important element to achieve continuing engagement and sustainability, but they must be developed by the local stakeholders based on their "needs" and "wants" while being feasible within the local environment. ${ }^{42}$

Although financial incentives are easily conceptualized and more tangible benefits to participation, they are challenging in the current resource-constrained environment of health care. Instead, in academic medical centres, this may take the form of ensuring that clinician-scholars in QIPS are given equal opportunity for academic advancement compared with their researcher and educator colleagues (e.g., as "clinician improvers"). This may be done through the celebration, promotion, and support of the academic dissemination of their work. ${ }^{43,44}$ At the hospital and health system levels, this may include nonmonetary improvement or leadership awards, work/ schedule arrangements, or cost savings being re-invested in the ED (i.e., gain-sharing approach), as well as career advancement for those who contribute to successful QIPS projects and improve the patient experience (e.g., supporting CPD or leadership opportunities). Indeed, the QIPS skills necessary for successful improvement processes are often transferable to leadership and administrative responsibilities.

\section{Recommendation 10. In centres with no QIPS experience, consider starting small by focusing on a project or specific deliverable instead of a program}

The recommendations outlined above can be modified and applied to a QIPS project or specific deliverable instead of a program of QIPS. A successful initiative can then be used as a foundation to change culture toward the acceptance of iterative and ongoing improvement work and building a QIPS program. Options for a foundational project include starting with a small, engaging, and feasible deliverable or collaborating with and supporting colleagues on a larger initiative.

When starting with a first QIPS initiative, ensure that it aligns with organizational priorities and make it relevant and engaging to stakeholders. Using a systematic approach such as the one elaborated in the CFEM QI Primer Series or by using the SQUIRE guidelines would improve the odds of success. ${ }^{33,40,45,46}$ Another key starting point is to identify QIPS training opportunities for health care providers and support staff. Initial training options include online and distance learning opportunities such as the Institute for Healthcare Improvement (IHI) open school. ${ }^{47}$ Stakeholder engagement including multi-disciplinary teams, leadership, administration, and patients and families would be particularly important in achieving a successful initial QIPS project or deliverable and building a culture that is supportive of quality improvement.

\section{CONCLUSION}

Continuously improving the delivery of health care services is essential, but difficult, and QIPS methodologies have been shown to increase the likelihood of success and sustainability of improvement projects. Our national needs assessment survey demonstrated a discrepancy between the current level of infrastructure and resources allocated to ED QIPS activities compared with the level of academic output and operational efforts. As the field and our community mature, there is an opportunity for ED providers and leaders to move away from stand-alone improvement projects and toward programs of QIPS in their ED. Our expert panel developed recommendations based on expert opinion, a scoping review, and involvement of QIPS experts. We also developed an online QIPS training repository, with the goal of providing EM practitioners with useful links, examples, and resources. Although many steps may occur concurrently and local setting will dictate adaptations, these recommendations provide guidance for the development of a program of QIPS in the ED. Our hope is that these recommendations will contribute to the advancement of the field of QIPS in EM in Canada and, ultimately, improve patient care.

Acknowledgements: The authors acknowledge the input of the 14 experts who helped refine the recommendations, who include (alphabetically): Paula Blackstien-Hirsch, Dr. Lisa Calder, Dr. Amy Cheng, Dr. Alan Gobb, Dr. Scott McKay, Dr. Michael Lewell, Dr. Rod Lim, Jackie Schleifer Taylor, Dr. Howard Ovens, Dr. Paul Pageau, Dr. Timothy Rutledge, Dr. Jennifer Thull-Freedman, Dr. Stephanie VandenBerg, and Dr. Jim Worthington, as well as Danielle Porplycia for her help with preparation of the manuscript.

Competing interests: None declared.

\section{REFERENCES}

1. Joint Commission. "Patient Safety System" Chapters. $7 t$ Comm. December 18, 2017. Available at: https://www. 
jointcommission.org/assets/1/6/PS_chapter_AHC_2018. pdf (accessed September 6, 2018).

2. Forrest CB, Glade GB, Baker AE, Bocian A, von Schrader S, Starfield B. Coordination of specialty referrals and physician satisfaction with referral care. Arch Pediatr Adolesc Med 2000;154(5):499-506.

3. Chartier L, Josephson T, Bates K, Kuipers M. Improving emergency department flow through rapid medical evaluation unit. BM7 Qual Improv Rep 2015;4(1).

4. Gandhi TK, Sittig DF, Franklin M, Sussman AJ, Fairchild DG, Bates DW. Communication breakdown in the outpatient referral process. 7 Gen Intern Med 2000;15 (9):626-31.

5. Gandhi TK. Fumbled handoffs: one dropped ball after another. Ann Intern Med 2005;142(5):352-8.

6. Schneider EC, Sarnak DO, Squires D, Shah A, Doty MM. Mirror, Mirror 2017: International Comparison Reflects Flaws and Opportunities for Better US Health Care; 2017. Available at: https://interactives.commonwealthfund.org/2017/july/ mirror-mirror/ (accessed April 11, 2019).

7. Schoen C, Osborn R, Doty MM, Bishop M, Peugh J, Murukutla N. Toward higher-performance health systems: adults' health care experiences in seven countries, 2007. Health Aff (Millwood) 2007;26(6):w717-34.

8. Stange KC. The problem of fragmentation and the need for integrative solutions. Ann Fam Med 2009;7(2):100-3.

9. Kohn L, Corrigan J, Donaldson M. To Err Is Human: Building a Safer Health System. (Committee on Quality of Health Care in America I of M, ed.). Washington, DC: National Academy Press; 2000.

10. Institute of Medicine, Committee on the Quality of Health Care in America. Crossing the Quality Chasm: A New Health System for the 21st Century. Washington, DC: National Academy Press; 2001, https://doi.org/10.17226/10027.

11. Kwok ES, Perry JJ, Mondoux S, Chartier LB. An Environmental Scan of Quality Improvement and Patient Safety Activities in Emergency Medicine in Canada. C7EM 2019; epub, 10.1017/cem.2019.16

12. Reinertsen JL, Bisognano M, Pugh MD. Seven Leadership Leverage Points for Organization-Level Improvement in Health Care (Second Edition). IHI Innovation Series white paper. Cambridge, MA: Institute for Healthcare Improvement; 2008.

13. Nolan TW. Execution of Strategic Improvement Initiatives to Produce System-Level Results. IHI Innovation Series white paper. Cambridge, MA: Institute for Healthcare Improvement; 2007.

14. Welch S, Klauer K, Fontenor SF. Setting up a Comprehensive Quality Improvement Program for your ED. Risk Management and the Emergency Department. Health Administration Press; 2011, 17-30.

15. Boyle A, Cleugh F, Long J, et al. Royal College of Emergency Medicine Quality Improvement Guide: A practical guide for clinicians undertaking quality improvement in Emergency Departments; 2016.

16. Reinertsen JL, Gosfield AG, Rupp W, Whittington JW. Engaging Physicians in a Shared Quality Agenda. IHI Innovation Series white paper. Cambridge, MA: Institute for Healthcare Improvement; 2007.
17. DeWalt D, Powell J, Mainwaring B, et al. Practice coaching program manual. Princeton, NJ: Aligning Forces for Quality (AF4Q), George Washington University Medical Center; 2010.

18. Canadian Patient Safety Institute. Tips for patient engagement in patient safety and quality committees. CPSI. February 24, 2016. Available at: http://www.patientsafetyinstitute. $\mathrm{ca} /$ en/toolsResources/pages/pfpsc-patient-engagement-insafety-committees.aspx (accessed September 6, 2018).

19. Institute for Healthcare Improvement. Science of Improvement: Forming the Team. IHI. June 6, 2012. Available at: http://www.ihi.org/resources/Pages/HowtoImprove/ScienceofImprovementFormingtheTeam.aspx (accessed September 6, 2018).

20. World Health Organization. Operations Manual for Staff at Primary Health Care Centres. Quality Improvement Chapter 11. December 2, 2008. Available at: http://www.who.int/ hiv/pub/imai/om_11_quality_improvement.pdf (accessed September 6, 2018).

21. Kaplan HC, Brady PW, Dritz MC, et al. The influence of context on quality improvement success in health care: a systematic review of the literature. Milbank Q 2010;88(4):500-59.

22. Alexander JA, Hearld LR. The science of quality improvement implementation: developing capacity to make a difference. Med Care 2011;49 Suppl:S6-20.

23. Kaplan HC, Froehle CM, Cassedy A, Provost LP, Margolis PA. An exploratory analysis of the model for understanding success in quality. Health Care Manage Rev 2013;38 (4):325-38.

24. Agency for Healthcare Research and Quality. The Guide to Improving Patient Safety in Primary Care Settings by Engaging Patients and Families. Rockville, MD: AHRQ; 2018. Available at: https:/www.ahrq.gov/sites/default/files/ wysiwyg/professionals/quality-patient-safety/patient-familyengagement/pfeprimarycare/pfepc-fullguide-final508.pdf (accessed September 6, 2018).

25. Singh R, Pace W, Singh S, Singh A, Singh G. A concept for a visual computer interface to make error taxonomies useful at the point of primary care. Inform Prim Care 2007;15 (4):221-9.

26. Farbstein K, Clough J. Improving medication safety across a multihospital system. Ft Comm $\mathcal{F}$ Qual Improv 2001;27 (3):123-37.

27. Health Quality Ontario. Quality Improvement Guide. Toronto (ON): Queens Printer of Ontario; 2012.

28. Varkey P, Reller MK, Resar RK. Basics of quality improvement in health care. Mayo Clin Proc 2007;82(6):735-9.

29. Kelly JJ, Thallner E, Broida RI, et al. Emergency medicine quality improvement and patient safety curriculum. Acad Emerg Med 2010;17 Suppl 2:e110-29.

30. Johnstone PA, Hendrickson JA, Dernbach AJ, et al. Ancillary services in the health care industry: is Six Sigma reasonable? Qual Manag Health Care 2003;12(1):53-63.

31. Frank JR, Snell L, Sherbino J, eds. CanMEDS 2015 Physician Competency Framework. Ottawa: Royal College of Physicians and Surgeons of Canada; 2015.

32. Mondoux SE, Chan TM, Ankel F, Sklar DP. Teaching Quality Improvement in Emergency Medicine Training Programs: A Review of Best Practices. AEM E \& T 2018;1(4). 
33. Chartier LB, Cheng AH, Stang AS, Vaillancourt S. Quality improvement primer part 1: preparing for a quality improvement project in the emergency department. CFEM 2018; 20(1):104-11.

34. Bryson JM. Strategic Planning for Public and Nonprofit Organizations: A Guide to Strengthening and Sustaining Organizational Achievement. 3rd ed. San Francisco: JosseyBass; 2004.

35. The Point of Care Foundation. 2018. Available at: https:// www.pointofcarefoundation.org.uk/resource/experiencebased-co-design-ebcd-toolkit/ (accessed September 6, 2018).

36. Rotteau L, Webster F, Salkeld E, et al. Ontario's ED improvement process program. Acad EM 2015;22(6):720-9.

37. Lynn J, Baily MA, Bottrell M, et al. The ethics of using quality improvement methods in health care. Ann Intern Med 2007 May;146(9):666-73.

38. Batalden $\mathrm{PB}$, Davidoff $\mathrm{F}$. What is "quality improvement" and how can it transform healthcare? Qual Saf Health Care 2007;16(1):2-3.

39. Berwick DM. Developing and testing changes in delivery of care. Ann Intern Med 1998;128(8):651-6.

40. Chartier LB, Vaillancourt S, Cheng AH, Stang AS. Quality improvement primer part 3: evaluating and sustaining a quality improvement project in the emergency department. CFEM. 2019;21(2):261-68.
41. Ham C, Kipping R, McLeod H. Redesigning work processes in health care: lessons from the National Health Service. Milbank Q 2003;81(3):415-39.

42. Scoville R, Little K, Rakover J, Luther K, Mate K. Sustaining Improvement. IHI White Paper. Cambridge, MA: Institute for Healthcare Improvement; 2016.

43. Shojania KG, Levinson W. Clinicians in quality improvement: a new career pathway in academic medicine. $\mathcal{F} A M A$ 2009;301(7):766-8.

44. Mondoux SE, Frank JR, Kwok ES, et al. Teaching M\&M rounds skills: enhancing and assessing patient safety competencies using the Ottawa M\&M model. Postgrad Med 7 2016;92(1093):631-5.

45. Chartier LB, Stang AS, Vaillancourt S, Cheng AH. Quality improvement primer part 2: executing a quality improvement project in the emergency department. CFEM 2018;20 (4):532-8.

46. Ogrinc G, Davies L, Goodman D, et al. SQUIRE 2.0 (Standards for QUality Improvement Reporting Excellence): revised publication guidelines from a detailed consensus process. BM7 Qual Saf 2016;25(12):986-92.

47. Institute for Healthcare Improvement. Open School. 2018. Available at: http://www.ihi.org/education/IHIOpenSchool/Pages/default.aspx (accessed September 6, 2018). 